\title{
THE EFFECTS OF AN ECO-DRIVING INTERFACE ON DRIVER SAFETY AND FUEL EFFICIENCY
}

\author{
Daryl L. Hibberd ${ }^{\mathrm{a}}$, A. Hamish Jamson ${ }^{\mathrm{a}}$ \& Samantha L. Jamson ${ }^{\mathrm{a}}$. \\ ${ }^{a}$ Institute for Transport Studies, University of Leeds, Leeds, LS2 9JT, U.K.
}

\begin{abstract}
Summary: Real-time, in-vehicle guidance on eco-driving is likely to produce substantial improvements in vehicle fuel economy. However, the benefits of such in-vehicle systems should be achieved without impairing driver safety. A simulator study evaluated both visual and haptic eco-driving feedback systems, which provided advice on gas pedal usage. Hill driving scenarios with variable traffic density were used to test drivers' prioritization of safe and fuel-efficient driving. A visual, second-order display and a haptic force feedback gas pedal created the smallest errors in gas pedal usage and so maximized fuel efficiency. The visual display increased time spent looking away from the road, implying reduced driver safety. Participants were worse at eco-driving in more demanding, high traffic conditions. Drivers appeared to prioritize safety over eco-driving, however safety margins were shorter in the high density traffic condition, despite the degradation in eco-driving performance. The findings suggest which modality could be most appropriate for presenting in-vehicle eco-driving guidance, and hint that these systems should advise drivers based on the prevailing traffic conditions.
\end{abstract}

\section{INTRODUCTION}

Road transport is one of the largest contributors to global greenhouse gas emissions (EEA, 2014). Reducing vehicle fuel consumption and thus the environmental cost of a journey, can be achieved by encouraging drivers to adopt fuel-efficient driving behaviours ('eco-driving'). Fuel savings of up to $20 \%$ could be possible with the provision of effective eco-driving guidance (Van der Voort et al., 2001), with real-time guidance likely to produce longer lasting results than pretraining (af Wåhlberg 2007).

This driving simulator study investigates three in-vehicle assistance systems that provide realtime guidance on fuel-efficient gas pedal usage. The systems advise drivers on current performance errors and the gas pedal action required to reduce fuel consumption (Gonders et al., 2011). Much of past research focuses on the provision of eco-driving guidance using colourcoded or numerical visual displays (Meschtscherjakov et al. 2009). This study includes one such system. However, evidence suggests that a continuous visual display can distract the driver, and impair event detection and vehicle control (Östlund, Nilsson et al. 2004). An appropriate invehicle eco-driving assistance system needs to provide useful advice to create fuel savings, but also should not encourage unsafe driver behaviours. Two haptic gas pedal interfaces are tested based on Mulder et al.'s (2008) force and stiffness feedback systems - due to their potential benefits for driver safety and workload relative to a visual display (Birrell, Young et al., 2010).

The objectives of this study were:

i) To determine the most effective interface type for delivering real-time eco-driving advice;

ii) To investigate potentially undesirable side-effects of interface interaction on driver safety. 


\section{METHOD}

\section{Apparatus}

The study was performed on the University of Leeds Driving Simulator, featuring a 2005 Jaguar S-type vehicle cab and fully-operational steering wheel, pedal and dashboard controls. A haptic gas pedal is installed, for which a series of pedal force and pedal travel profiles can be defined, with pedal feedback up to $200 \mathrm{~N}$. The driving scene is projected on the inside wall of a $4 \mathrm{~m}$ dome ( $250^{\circ}$ forward view and $40^{\circ}$ rear, $60 \mathrm{~Hz}, 1024 \times 768$ resolution). Motion cues associated with acceleration and cornering are created via an 8-degrees of freedom motion system. Realistic engine and environmental noise is presented. Gaze direction was recorded using a Seeing Machines faceLAB v5.0 system.

\section{Eco-driving systems}

Three eco-driving interfaces were designed to provide real-time guidance on fuel efficient gas pedal use. Pilot studies were conducted (e.g. Hibberd et al., 2013) to select the most effective, useful, acceptable and least distracting interfaces (Peters and Peters, 2002), based on the principles of persuasive feedback and Ecological Interface Design (Meschtscherjakov et al. 2009). All three systems provided guidance based on the same underlying 'eco-driving algorithm'. The system required a specific gas pedal angle for fuel-efficient acceleration (15\% depression), deceleration ( $0 \%)$ and cruising (7\%).

Visual eco-driving system. A colour-coded and dynamic visual eco-driving interface (Gonder et al., 2011) was presented in the centre of the tachometer. This second-order display provided information about accuracy of gas pedal position and the magnitude of the change required to optimize fuel efficiency. A foot icon (approximately $3 \mathrm{~cm} \mathrm{x} 3 \mathrm{~cm}$ ) changed colour depending on the efficiency of the current gas pedal position (green $=$ good, red/blue $=$ improvement possible). The colour blended between the three options over a $5 \%$ range, such that a pedal error of $+6 \%$ or $-6 \%$ would produce a pure red or blue foot symbol respectively. The green symbol was presented for pedal errors between $+1 \%$ to $-1 \%$ (Figure 1 ). The display included two lines representing the actual (grey line) and desired gas pedal angles (dotted line). These two lines moved in real-time to show the discrepancy between the current and desired pedal position. Successful eco-driving was shown by a green foot icon and two pedal lines overlapping.
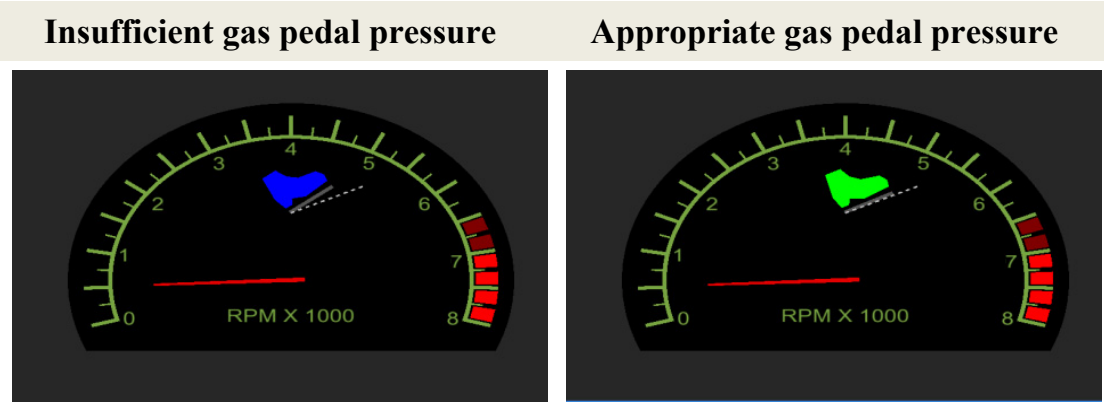

\section{Excessive gas pedal pressure}

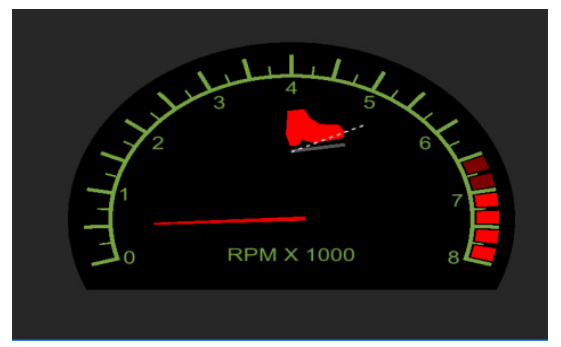

Figure 1: Visual eco-driving system 
Haptic eco-driving systems. The haptic force and haptic stiffness feedback systems change the proportional relationship seen in a typical vehicle between the force applied to the gas pedal and the pedal travel. The resistance of the gas pedal was varied depending on the fuel efficiency of current performance. The haptic force system warns of excessive acceleration by requiring a significant extra force $(40 \mathrm{~N})$ to be applied to increase gas pedal depression beyond the angle considered most fuel efficient. The gas pedal angle at which this step-change in force occurred varied for acceleration, deceleration and cruising phases. The haptic stiffness system resisted excessive acceleration through a distinct change in pedal stiffness rather than an instantaneous increase in required pedal force. The standard $0.2 \mathrm{~N}$ increase in pedal force required for a $1 \%$ movement of the gas pedal was increased to a $2.9 \mathrm{~N}$ force. Both systems informed the driver of insufficient gas pedal depression by reducing gas pedal resistance.

\section{Driving scenarios and tasks}

Participants drove on a simulated two-lane motorway (speed limit 70mph) including six hill sections $(1000 \mathrm{~m}$, ascent/descent profile $=4 \%)$ interspersed with flat sections. Hills were selected

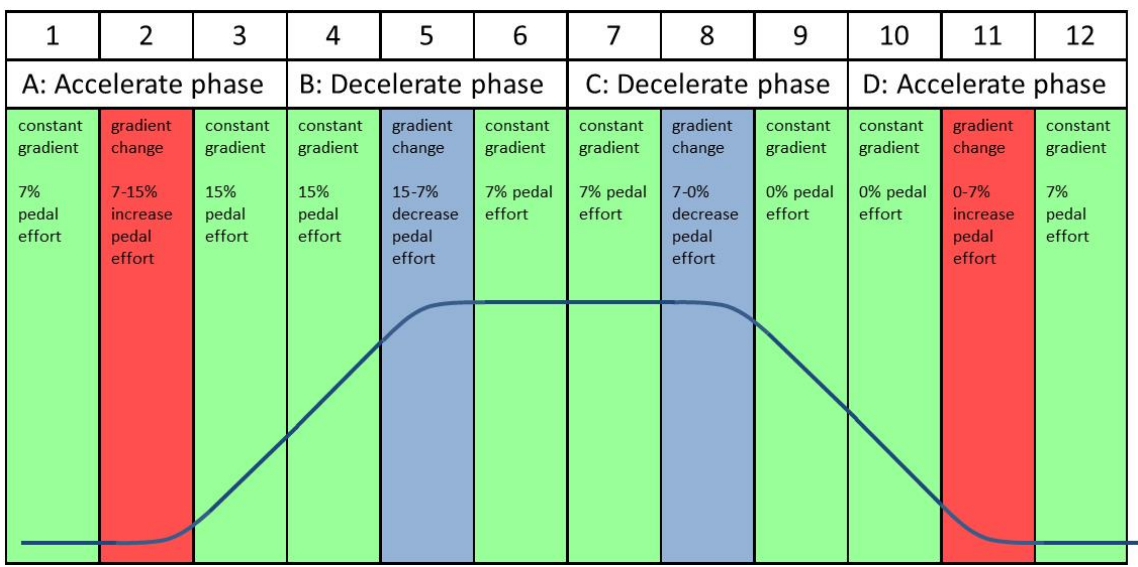

Figure 2: Hill scenario (Colours represent required gas pedal action) as a test case due to the variation in gas pedal position required for fuel efficient driving on the ascent, flat and descent sections of the scenario. Figure 2 shows the route profile and the required gas pedal angle to optimize fuel efficiency at each stage. The ecodriving systems provided advice to guide drivers towards these desired gas pedal angles. Drivers were instructed to adjust their use of the gas pedal in order to optimize fuel efficiency throughout the drive. They were informed that high fuel efficiency could be achieved by following the ecodriving advice, and not through selection of an 'eco-speed'. This equated the target speed across participants. Low and high density traffic (800 and 1600 vehicles per lane per hour respectively) were each present in three hill scenarios (order counterbalanced). The system did not account for the volume and position of surrounding traffic when issuing guidance, thus it was the drivers' decision on whether to follow system guidance when doing so could compromise their safety margin. In high traffic, drivers could only follow the eco-driving system guidance by accepting a reduced time headway $(<2 s)$. Eco-driving task performance between traffic conditions allowed an assessment of the prioritization of safety and eco-driving. It was assumed that drivers would work to avoid crashing into the lead vehicle, and thus a safe driving vs. eco-driving trade-off would be enforced upon them in the high traffic condition. 


\section{Experimental design and procedure}

A within-subjects design was selected in which each participant drove once with each ecodriving system and once without a system (four drives, $25 \mathrm{~min}$ each), with the order of drives counterbalanced. Participants had a practice drive to familiarize themselves with the simulator vehicle and eco-driving systems. The experimental drives were interspersed with rest periods. After each drive, subjective workload data (NASA-TLX, Hart \& Staveland, 1988) and system acceptability data (Van der Laan, Heino \& De Waard, 1997) were collected. Workload and system acceptability scores were calculated using a summation of the sub-scales of these metrics.

\section{Participants}

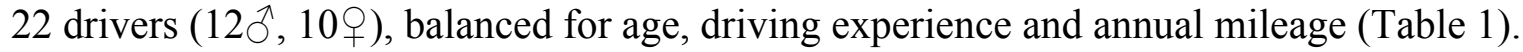

Table 1: Participant sample characteristics

\begin{tabular}{ccccccccc}
\hline & \multicolumn{4}{c}{ Male (n=12) } & \multicolumn{4}{c}{ Female (n=10) } \\
\cline { 2 - 9 } Age (years) & Mean & SD & Max. & Min. & Mean & SD & Max. & Min. \\
Experience (years) & 34 & 11 & 59 & 22 & 40 & 15 & 67 & 22 \\
Annual mileage (mi) & 11700 & 5900 & 25000 & 6500 & 7150 & 3650 & 15000 & 3000 \\
\hline
\end{tabular}

\section{Data collection}

Driving performance data were analyzed from hill sections of the road only. Root mean squared gas pedal error was the measure of eco-driving task performance accuracy. This is the difference between current and system-desired gas pedal angle (or for the baseline drive, the angle that would be desired if a system were present). Small errors indicate successful adherence to the eco-driving advice, and high fuel efficiency. Percent Road Centre (PRC) - a measure of visual distraction - indexes the proportion of an individual's gaze fixations that fall within a $6^{\circ}$ circular region centred on the driver's modal fixation location (Victor et al., 2005).

\section{RESULTS}

Parametric data analysis assumptions were met. Each variable was subjected to twoway repeated measures ANOVA with independent measures of System (4 levels), and Traffic Density (2 levels). Data were pooled across hill repeats. The GreenhouseGeisser correction was applied for spherical data. Post-hoc Bonferroni-corrected pairwise comparisons were performed.

\section{Objective data}

A significant main effect of System was observed on root mean squared gas pedal error $\left[F(3,60)=11.81, \mathrm{p}<.001, \eta^{2}=.37\right]$.

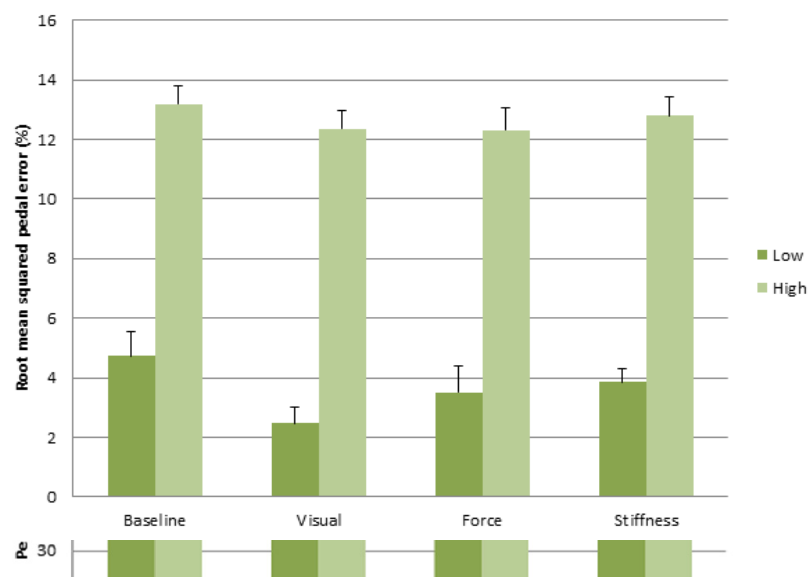

Figure 3: Root mean squared pedal error by System and Traffic Density

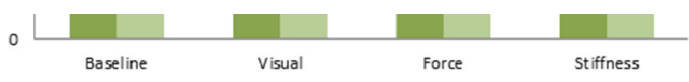

Figure 4: Percent road centre by System and Traffic Density 
Errors during baseline driving $[\mathrm{M}=9.0 \%]$ were significantly higher than with the visual $[\mathrm{M}=7.4 \%]$ or haptic force $[\mathrm{M}=7.9 \%]$ systems. Performance with the visual interface also exceeded that with the haptic stiffness system $[\mathrm{M}=8.3 \%]$. Drivers produced significantly larger pedal errors in the high traffic condition $[\mathrm{M}=12.6 \%]$ compared to the low traffic condition $[\mathrm{M}=3.6 \%],\left[\mathrm{F}(1,20)=1553.47, \mathrm{p}<.001, \eta^{2}=.99\right]$. A significant System $\mathrm{x}$ Traffic Density interaction showed that the effect of System is greater in low density traffic conditions $\left[\mathrm{F}(3,60)=3.74, \mathrm{p}=.016, \eta^{2}=.16\right]$ (Figure 3 ). Percent road centre was affected by System, $[\mathrm{F}(3,54)=25.67, \mathrm{p}<.001, \eta 2=.44]$, with significantly lower time spent fixating on the road centre when driving with the visual display $[\mathrm{M}=58.9 \%]$ compared to all other conditions $[\mathrm{M}=71.1 \%$ (haptic force); $71.8 \%$ (haptic stiffness), $67.2 \%$ (baseline)]. PRC was significantly greater in the high density traffic condition than the low density traffic, $[F(1,17)=65.71, p<.001, \eta 2=.80]$. A significant System x Traffic Density interaction, $[\mathrm{F}(3,51)=4.49, \mathrm{p}=.007, \eta 2=.21]$, showed a greater increase in attention to the road centre with increasing traffic density with the visual system $[\mathrm{M}=+14.8 \%]$ compared to the other conditions, $[\mathrm{M}=+7.7 \%$ (haptic force); $+9.8 \%$ (haptic stiffness), $+7.4 \%$ (baseline)] (Figure 4).

Minimum headway was significantly shorter in high density traffic $(\mathrm{p}<.05)$ and an interaction of System $x$ Traffic Density showed the shortening to be greater with the visual interface (Table 2).

\section{Subjective data}

Subscales of the NASA-TLX were summed to provide a total workload score (max. 60). Non-parametric Friedman's ANOVA with Wilcoxon Signed Rank posthoc tests, corrected for multiple comparisons showed a significant effect of System on perceived workload,

Table 2: Minimum time headway (seconds) per System

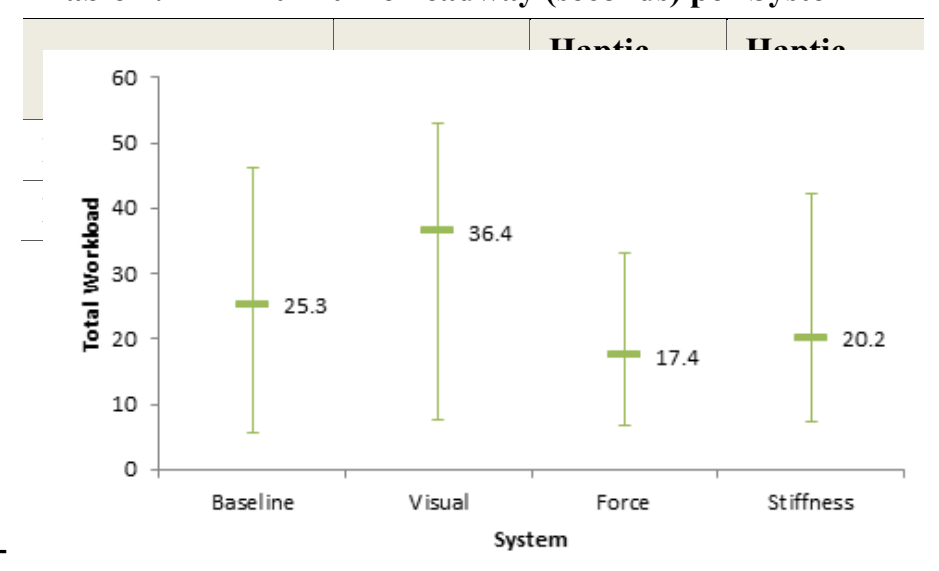

Figure 5: Median total workload score by System (errors bars display range) $\mathrm{x} 2(3)=26.56, \mathrm{p}<.001$. The haptic force system was rated as producing lower workload than the haptic stiffness and visual systems, and no system. The visual system created greater workload than when driving with the haptic stiffness system or no system (Figure 5). Acceptance ratings were summed across the five System Usefulness items and across the four System Satisfaction items. Friedman's ANOVA revealed the visual interface to be more useful $[\mathrm{x} 2(2)=10.70$, $\mathrm{p}=.005]$ and more satisfying, $[\mathrm{x} 2(2)=12.36, \mathrm{p}=.002]$ than the two haptic interfaces.

\section{DISCUSSION}

This driving simulator study investigated the relative effectiveness of three eco-driving support systems and the extent to which drivers follow their advice in varied traffic conditions. Results show that both the visual and haptic force feedback interfaces had the greatest impact on drivers' control of the gas pedal (reduced position errors), and thus improved fuel efficiency the most. Anecdotal feedback hinted that the more subtle cues of the haptic stiffness system often led to participants removing and replacing their foot on the gas pedal to receive additional feedback to 
confirm the accuracy of their chosen pedal position, hence increasing pedal error. The haptic force system provided more unequivocal guidance on efficient gas pedal position.

An assessment of eco-driving system effectiveness should consider its impact on driver safety. Drivers spent longer looking at the road centre when using the haptic interfaces compared to the visual interface, suggesting that despite being effective for delivering eco-driving guidance, the visual modality had a damaging effect on a driver's attention to the roadway, which could in turn affect vehicle control (Merat and Jamson, 2008). Encouragingly, there was evidence to suggest that drivers looked at the road ahead for longer when using a haptic eco-driving interface than no interface, perhaps due to a reduced need to consult the dashboard for speed information.

The extent of drivers' prioritization of eco-driving and safe driving was assessed by placing participants into low traffic (where good adherence to the eco-driving advice was possible without accepting a shorter headway) and high traffic (where good eco-driving relied on acceptance of a shorter headway). Gas pedal errors were larger in high traffic suggesting that drivers prioritized safety over fuel savings when the challenge of maintaining a safe distance to the vehicle in front increased. An interaction of System x Traffic Density on percent road centre showed that the increase in looking towards the road centre between the low and high density conditions is substantially larger for the visual interface compared to either haptic interface. This shows that drivers appear to be aware of the negative impacts of a visual display on their safety and change their behaviour to attempt to compensate for this in demanding traffic conditions. However, whilst it is encouraging that drivers appear to abandon the eco-driving task and focus on safety in busy traffic, there is doubt over the success of this strategy. Minimum headway was shorter in high density traffic, with this reduction in the safety margin being more pronounced during interaction with the visual interface. This result suggests a more complex pattern of behavior than the driver simply adopting eco-driving practices when they have sufficient space in front of them, and then neglecting them when the safety margin to the lead vehicle is threatened. It would appear that drivers still attempt to follow eco-driving guidance and their compensatory strategies are insufficient. As a result, it is important that future eco-driving assistance systems offer guidance which accounts for the prevailing traffic conditions, or at least warn of the potential dangers of following the advice in busy traffic.

Workload ratings show that drivers found the visual interface more demanding to interact with. Subjective performance was rated lower with the visual display, despite better objective performance than either haptic system. It is encouraging to see that haptic eco-driving interfaces imposed low workload on the driver. However, it should be noted that the visual interface in this study required high attention to successfully follow the proposed advice, and a focus on the design of a less content-rich display could yield more positive results. The acceptability ratings are less favourable for the two haptic systems, with the visual interface rated more useful and satisfying. A combined visual-haptic eco-driving assistance system could be an option for designing a system that not only improves driver performance but is acceptable to use.

There are some limitations that should be acknowledged before attempting to apply the results of this work in a real-world context. There were some instances of congestion in the high density drives that prevented successful following of the eco-driving guidance, even with a reduced safety margin. Furthermore, the high salience of the eco-driving task in this study may affect the 
relative prioritization of eco- and safe driving, compared to everyday driving. Future work could also involve a more realistic eco-driving algorithm and a wider range of driving scenarios in which fuel savings could be possible with the use of eco-driving behaviours.

\section{REFERENCES}

af Wåhlberg, A. E. (2007). Long-term effects of training in economical driving: Fuel consumption, accidents, driver acceleration behavior and technical feedback. International Journal of Industrial Ergonomics 37(4): 333-343.

Birrell, S. A., M. S. Young, et al. (2010). Delivering smart driving feedback through a haptic pedal. Contemporary Ergonomics and Human Factors: Proceedings of the International Conference on Contemporary Ergonomics and Human Factors, pp.431-439.

European Environment Agency (2014). Annual European Union greenhouse gas inventory 1990-2012 and inventory report 2014. EEA Technical report. Luxembourg.

Gonder, J., Earleywine, M. \& Sparks, W. (2011). Fuel saving effectiveness of various driver feedback approaches. Final Report NREL/MP-5400-50836, National Renewable Energy Laboratory, U.S. Department of Energy Office of Scientific and Technical Information.

Hart, S. G. \& Staveland, L. E. (1988). Development of NASA-TLX (Task Load Index): Results of Empirical and Theoretical Research. Advances in Psychology. P. A. Hancock and N. Meshkati, North-Holland. Volume 52: 139-183.

Hibberd, D., Jamson, H., et al. (2013). Deliverable document D12.1: Multi-modal in-vehicle and nomadic device eco-driving support for car drivers and truck drivers. ecoDriver Project.

Merat, N. and Jamson, H. (2008). The effect of stimulus modality on signal detection: Implications for assessing the safety of in-vehicle technology. Human Factors, 14, 145-158.

Meschtscherjakov, A., D. Wilfinger, et al. (2009). Acceptance of future persuasive in-car interfaces towards a more economic driving behaviour. Proceedings of the 1st International Conference on Automotive User Interfaces and Interactive Vehicular Applications. Essen, Germany, ACM: 81-88.

Mulder, M., van Paassen, M. M., et al. (2008). Haptic gas pedal feedback. Ergonomics 51(11), 1710-1720.

Östlund, J., L. Nilsson, et al. (2004). Deliverable 2-HMI and Safety-Related Driver Performance. HASTE Project.

Peters, G. A. and B. J. Peters (2002). Automotive Vehicle Safety. London, Taylor \& Francis.

Van Der Voort, M., Dougherty, M. S. \& Van Maarseveen, M. (2001). A prototype fuelefficiency support tool. Transportation Research Part C, 9, 279-296.

Van Der Laan, J. D., Heino, A. \& De Waard, D. (1997). A simple procedure for the assessment of acceptance of advanced transport telematics. Transportation Research Part C, 5(1), 1-10.

Victor, T., Harbluk, J. L., and Engström, J. A. (2005). Sensitivity of eye-movement measures to in-vehicle task difficulty. Transportation Research Part F 8(2), 167-190. 